\title{
Relationship Matters: Duo-narrating a Graduate Student/Supervisor Journey
}

\author{
Mary Breunig ${ }^{1}$, Joyce Penner ${ }^{2}$ \\ ${ }^{1}$ Department of Recreation and Leisure Studies, Brock University, St. Catharines, Canada \\ ${ }^{2}$ Social Justice and Equity Studies, Brock University, St. Catharines, Canada \\ Correspondence: Mary Breunig, Department of Recreation and Leisure Studies, Brock University, St. Catharines, \\ Canada
}

Received: January 25, 2016 Accepted: February 27, 2016 Online Published: March 18, 2016

doi:10.11114/jets.v4i6.1330 URL: http://dx.doi.org/10.11114/jets.v4i6.1330

\begin{abstract}
The student/supervisor relationship may be one of the most important aspects of graduate student success; yet, few academics receive any training in student supervision. Students may not know what qualities and capacities to consider when choosing a supervisor. The purpose of this paper is to duo-narrate the story of our experiences with a Social Justice and Equity Studies master's thesis project at a Canadian University focusing on student/supervisor relationship-building. In this collaborative endeavor we share stories of our experiences in an effort to communicate the centrality of "relationship" in the student/supervisor collaboration. We provide personal and literature-based insights into graduate supervision, including lessons learned and advice(s) for both faculty and students about: 1) relationship matters; 2) the value of communication; and 3) the importance of culture and context.
\end{abstract}

Keywords: student/supervisor relationship, graduate scholarship, narrative

\section{Introduction}

The student/supervisor relationship may be one of the most important aspects of graduate student success (Grose, 2011; Jairam \& Kahl, 2012; Mishna \& Rasmussen, 2001; Spaulding \& Rockinson-Szapkiw 2012); yet, few academics receive any training in student supervision (Amundsen \& McAlpine, 2009; Garnder \& Barnes, 2014; Jairam \& Kahl, 2012). Students may not know what qualities and capacities to consider when choosing a supervisor, being unfamiliar with the task ahead and daunted by the prospect of graduate school (Lovitts, 2001; Gardner \& Barnes, 2014). The purpose of this paper is to duo-narrate the story of our experiences with a Social Justice and Equity Studies master's thesis project at a Canadian University, focusing on the centrality of student/supervisor relationship-building. In this collaborative endeavor the master's student and supervisor share stories of their experiences through written vignettes, which will be further explicated in the Methods section.

We first introduce ourselves, the authors, below. Throughout this paper, the supervisor's commentary will appear in italics and the student's remarks will appear in plain text.

\subsection{The Authors}

I, (Mary), am an Associate Professor at a mid-sized Canadian University. The focus of my scholarship is social and environmental justice. The path that led me to this employment did not follow an obvious trajectory. I, in fact, have spent most of my career as a wilderness trip guide, working for several notable outdoor schools, including Outward Bound and the National Outdoor Leadership School. I now spend my time as a Recreation and Leisure Studies Professor and graduate student supervisor in the Social Justice and Equity Studies program.

I, (Joyce), am a recent Social Justice \& Equity Studies master's graduate from a mid-sized Canadian University. My path to this endeavor was also not an obvious trajectory. My undergraduate degree was in psychology (from the same university). Throughout my undergraduate degree and for four years after, I worked in the social service sector. Currently I spend much of my time volunteering and renovating my new home. My thesis is entitled, Anachronistic Me: An Autoethnography of Recovery from Brain Injury through Volunteering at a Homeless Shelter. In it, I explore the ways in which my recovery from a traumatic brain injury (from a motor vehicle accident) was aided by the personal connections I made while volunteering in a homeless shelter pre- and post- accident. Particularly poignant, but holding 
less relevancy to this paper, is the way in which homeless guests at the shelter helped me (re)locate myself during a time of memory displacement (Penner, 2014).

As mentioned above, the focus of this paper is to duo-narrate the story of our experiences with a Social Justice and Equity Studies master's thesis project at a Canadian University, focusing on the centrality of student/supervisor relationship-building. We provide a literature review relevant to graduate supervision and mentorship. We then provide an overview of the conceptual/narrative research design we employed in this exploration followed by the vignettes themselves. The final section of this paper summarizes the scholarly significance and the ways in which this paper adds to the body of scholarship of teaching and learning and graduate mentorship knowledge, including practical advice.

\section{Literature Review}

A simple google search of "student-supervisor relationship and graduate work" reveals some interesting commentary relevant to the graduate experience. A number of university websites immediately pop up with useful advice and tips. Many of these sites assert that graduate student relationships with faculty members are regarded by students as the most important aspect of their graduate education going on to claim that strong student-supervisor relationships are also associated with higher completion rates and faster times to completion. According to one university, a great supervisor oversees the student's academic work, is passionate about the student's subject area and invested in her success. Fundamental elements of successful graduate supervision include: clear and frequent communication; agreement on mutual expectations; mentoring tailored to the needs, attributes and aspirations of each student; and a relationship that moves students closer to their goals. Many of the websites also emphasize that this is not always an easy relationship to negotiate given the high academic stakes. Several textbooks, predominantly focused on doctoral student supervision, provide commentary on how to advise doctoral students (see Gardner \& Barnes, 2014, among others), offering little advice focused on masters' students per se.

Academic magazines, such as University Affairs and the Chronicle of Higher Education have an array of advice articles about choosing a supervisor, supervising a student, and pitfalls to avoid. In one University Affairs article (Galt, 2013), the University of Toronto ombudsperson indicated that graduate students frequently visit her office with concerns about supervisors, including: slow feedback on drafts, inadequate or inconsistent direction, and the supervisor being unavailable for consultation. Some students complain about the time they are requested to invest in contracts for the supervisor's company at the expense of progress on their thesis. The ombudsperson went on to report that she is rarely authorized to investigate most concerns further, citing the power imbalance and fears that any action will only exacerbate the situation. Dr. Martin Kreiswirth, dean of graduate and postdoctoral studies at McGill University confesses that supervision is something that Canadian universities have only recently started to pay attention to in an analytic and systematic way (Galt, 2013). In the U.K. and Australia, for example, institutional accountability is formalized in government codes of practice. The Oxford Learning Institute Website is one that holds international appeal as a reference site for both graduate students and professors, including practical tips and "real life" case studies. There exist no similar code of practice or information clearinghouse in Canada when compared to the U.K. and Australia (Galt, 2013).

There are many factors that contribute to and detract from positive student-supervisor experiences and program success. Findings from one study (Spaulding \& Rockinson-Szapkiw, 2012) suggest that when selecting a graduate supervisor, students should consider personality and communication style in addition to faculty expertise. In a desirable supervisory situation, a supervisor supplies appropriate degrees of encouragement, advice, support, constructive criticism, appraisal, pastoral care, and aids in developing thinking and new ways of working (Gill \& Burnard, 2008; Mainhard, van der Rijst, van Tartwijk, \& Wubbels, 2009). According to these same authors, students benefit most when a supervisor has strong listening skills, encourages argument and debate, provides continuous feedback and support, and when he/she is enthusiastic, shows warmth and understanding, is professional, caring, and supportive. It is perhaps surprising then that academics typically have had no formal training in supervising students, particularly in light of the (above) daunting array of requisite capacities (Fraser \& Mathews, 1999; Gray \& Jordan, 2012; Hemer, 2012).

Also interesting to note is that beyond the university website anecdotes and some of the advice-driven columns found in the academic magazines, there remains a paucity of research exploring the student/supervisor relationship directly. Much of the literature offers conclusions about how to increase student retention and shorten degree completion timelines, suggesting that relationship is one of the most important aspects of the equation; yet offering little direct exploration of this key factor (Jairam \& Kahl, 2012; Spaulding \& Rockinson-Szapkiw, 2012). The relevant research literature that has previously explored relationship as key to thesis success and efficacy, reveals three main themes: 1) realistic expectations; 2) mentoring/relationship matters; and 3) leveling the power dynamic. Noteworthy in both the advice-based and empirical literature is its almost singular focus on doctoral studies with little investigation of those students in the more heavily populated master degree programs. 


\subsection{Realistic Expectations}

Both the student and the supervisor need to have realistic expectations of one another for the cultivation of a beneficial supervisory-student relationship (Gill \& Burnard, 2008; Mainhard, van der Rijst, van Tartwijk, Wubbels, 2009; Skarakis-Doyle \& McIntyre, 2008). Realistic expectations are co-created through clear, consistent communication. Gill and Burnard (2008) go on to assert that written documentation, regular meetings, and clear timelines can help support student success. That said, effective communication is far more complex than simply adhering to these guidelines. Students are navigating new terrain when they conduct research at universities and may not even be aware of the etiquettes, language, formalities, ethics and concepts that comprise the unwritten/hidden curriculum inherent in institutions (PsychCentral, 2015). Professors have numerous student supervisions and research projects happening simultaneous to one another and each student is vying for funding and time. Many students experience imposter syndrome early on in their academic pursuits (American Psychological Association, 2015; Grose, 2011) and this becomes more acute without the supervisor's navigational assistance. Finding the appropriate blend of affiliation, guidance, freedom, criticism and encouragement is no doubt difficult especially when each student requires differing degrees of each of the above to maximally perform.

De Kleijn, Mainhard, Meijer, Pilot, and Brekelmans' (2012) found that students achieved the highest marks in graduate school when they perceived high affiliation with their supervisors and a carefully balanced amount of control. Control was defined as the degree to which the supervisor directed the initiative. In their study, it was concluded that the students appreciated a degree of control until such time as their own agency was at risk and then, control became a negative attribute. Taylor and Dawson (2010) concluded that it is beneficial for supervisors to recognize that students are capable of research and to let students perform the research that they set out to do in partnership, trying to facilitate it in such a manner as to result in little-to-no-loss in student agency. Determining realistic expectations and finding a control/agency balance remains a tricky equation. Establishing a positive working relationship and co-determining expectations and balance are critical to the early stages of graduate work (Gardner \& Barnes, 2014). In another study, Lovitts (2001) concluded that students wished for a collaborative approach and a relationship that was mentor-student oriented. This expectation will be explored in the next section.

\subsection{Relationship Matters}

Supervisors are mentors and guides of scholarly journeys (Gray \& Jordan, 2012; Mishna \& Rasmussen, 2001). Supervisors play an important role in shaping students' academic behavior, rigor, work ethic, and integrity (Gray \& Jordan, 2012). One recent and comprehensive study at McGill University in Canada surveyed 424 graduate students and supervisors (including some follow-up interviews), concluding that there is incontestable evidence that an open and constructive student-supervisor relationship is a key factor to graduate student success. When this relationship does not go smoothly it has an adverse impact on all those involved particularly graduate students whose future careers rely on the success of this relationship, according to this Post-Graduate Students' Society of McGill University (PGSS) report (2014).

Communication, conflict resolution, and training for students and supervisors were highlighted as essential elements of that relationship. A relational approach to supervision can have significant impacts for a student, helping to allay feelings of isolation, which are ubiquitous and pervasive in academia (Armstrong, Allinson \& Hayes, 1997; Grose, 2011). Grose summarizes this in writing:

Role ambiguity, a lack of preparation for responsibilities, the need for mentorship and socialization, communication challenges, ethical dilemmas, feelings of impostership, and the desire for feedback are all signifiers of an absence or dearth of supports. (p. 138)

Adopting an affiliation/ relational approach to supervision and mentoring can help reduce these imposter feelings and feelings of isolation. Co-defining roles and responsibilities and communicating transparently about learning/teaching styles and work ethics, helps to establish expectations and build relationship (Lovitts, 2001).

\subsection{Leveling the Power Dynamic}

Traditionally, models of supervision have included structures of domination and disempowerment (Taylor \& Dawson 2010), expert and disciple, and/or master and apprentice (Hemer, 2012). When these models are applied, the student is often forced to relinquish control to the supervisor (Hemer, 2012). The student may feel compelled to carry out the supervisor's wishes and to please the supervisor rather than pursue her own research interests and approaches. The following student journal passage highlights this, emphasizing how this particular student felt constrained by her supervisor, writing, "It really is impossible [for you] to be emancipatory and non-coercive. You have all the power. It's the same way with my students. They go through my [teaching assistant] hoops and I go through yours" (Taylor \& Dawson, 2010, p. 113). One study that investigated the role of social support for 31 doctoral students working toward 
successful doctoral degree completion (Jairam \& Kahl, 2012), reported that faculty members often do not initiate interpersonal relationships with students. Additionally, students reported that faculty often behave inappropriately by openly debating, imposing values, and communicating in a threatening and aggressive manner. Interestingly, one study (Lovitts, 2001) found that students who selected their supervisor experienced greater academic success than those that were assigned a supervisor. Supervisors who took interest in students personally and supported them intellectually resulted in higher student completion rates according to this study's results.

Students most often appreciate a supervisor who collaborates with them, offering expertise to enhance the student's research study, balancing both creativity and criticism (Fraser \& Mathews, 1999; Lovitts, 2001). Dual dimensions of supervision include aiding in the production of a thesis and academic rigor but also nurturing a student in his intellectual maturity. Hemer (2012) refers to the process whereby a supervisor expresses both support and empathy without compromising direct (and sometimes even assertive) feedback as compassionate rigor. A growing number of student-supervisor duos are placing a greater emphasis on this, engaging in collaborative processes rather than falling back on traditional models which perpetuate rigid power structures (Fraser \& Mathews 1999; Hemer, 2012; Taylor \& Dawson, 2010).

\subsection{Conclusion}

The supervisor-student relationship is a powerful force in a student's graduate career. It can be one of uneven power dynamics, isolation or paralysis or it can encourage and enable students to be their best researcher-selves (Armstrong, Allinson \& Hayes, 1997; Gardner \& Barnes, 2014; Lovitts, 2001). Consideration of realistic expectations, relationship matters, and power dynamics can help build successful, collaborative partnerships between students and supervisors.

\section{Methods}

The methods employed are a conceptual/qualitative blend with a focus on narrative.

\subsection{Conceptual/Narrative}

While both conceptual and qualitative research seek to understand and articulate the experiences of how people experience a phenomenon (Patton, 2014), conceptual is about thinking and then writing rather than collecting data. Narrative research uses stories about a significant aspect of one's life to make sense of the experience (Polkinghorne, 1988). Narrative research emphasizes the interpretive power of stories to illuminate human meaning (Charmaz \& McMullen, 2011). David Silverman (1998) observes that what matters to the narrative researcher is to understand how and where a story is produced and in the story-telling, a narrator intelligently uses the narrative to theorize about an aspect of social life.

Paul Atkinson (1990) talks about the way in which ethnographers write down stories in the field and then go home to their studies and write those stories up: "writing down" and "writing up." He goes on to describe how what was written down is treated as data by the ethnographer within the imagery of "transcription uninterrupted by self-conscious intervention or reflection" (p. 61). Norris, Sawyer, and Lund (2012) suggest that duoethnography is a collaborative research methodology in which two or more researchers create a dialogic narrative to provide multiple understandings of a phenomenon. This dialetic process is also designed to be transformative to the writers (Norris, Sawyer, and Lund, 2012). It is in the spirit (proposed by Atkinson, 1990) of writing something down as data that we write up the following duo-narration. The narrative/results that follow consist of our process with what we describe as a back and forth reflexivity, illuminating our student/supervisor experiences. The way in which we present this next section is a mostly unedited version of that duo-narration wherein Joyce and I essentially wrote back and forth to each other, reading what the other wrote and responding, adding, or redirecting our reflexive conversation. It is our hope that the "writing down" and "writing up" of these experiences will highlight new ways of thinking about the student-supervisor relationship and identify the ways in which we both were formed and transformed by our enhanced understandings of one another.

\section{Narrative/Results}

Mary: I met Joyce through a chance encounter. She greeted me with a beaming smile in the hallway of the University. I did not know who she was but she looked as though she knew who I was. She then told me she had just seen me on a YouTube video accepting a teaching award from the Association for Experiential Education, inquiring if I would consider supervising her for a master's thesis.

Joyce: I met Mary soon after handing in my Social Justice and Equity Studies (SJES) program application. The online application requested that prospective students cite one or two professors to serve as potential supervisors. Thus, I had researched Mary earlier in the month and requested her. I knew her through YouTube teaching award speeches which were very engaging. Upon our chance meeting, my immediate thought was, "She isn't scary at all! How can someone brimming with this much career and pedagogical success not be scary???" When I received my acceptance into the program, I was ecstatic to read that Mary was going to be my SJES supervisor. 
Mary: I remain surprised when students contact me to be their supervisor and it is surprising here too to hear Joyce's perception of me as an academic. I still primarily see myself as a wilderness trip guide, which has been (and still is) my profession. Joyce and I were able to connect early on regarding this pursuit as I learned that her brother had done many of the first ascents of local climbing routes. There seemed to be an initial kinship although I did worry a bit, having never supervised a part-time student and wondering how prolonged the process would be. I also have never supervised someone with a brain injury although I have worked in both wilderness and group home settings with people with brain injuries. There was nothing similar between those experiences and my meeting Joyce. What will it be like? Will the supervision be different? Will I be different? Should I be? Will my direct style of feedback and the intensity I bring to student/supervisor exchanges "fit" with Joyce's style and needs? Are these considerations any different to any student/supervisor relationship I enter into? Not really, I realized.

Joyce: My concerns were not quite as lofty. I was concerned with my Hotmail account. I was not thrilled at the thought of using my Hotmail account for correspondence between university personnel and myself. I felt quintonowen@hotmail.com (my old yellow-lab's first and middle name), reeked of unprofessionalism. Thus, at the beginning of my graduate career I opened a new gmail account (my first, middle, and last name - clearly more professional, yes?). I gradually transitioned from daily use of my Hotmail account, which had served me well since I was 14 years old, trying to settle into a familiarity with my new email system....

Mary: I never knew that there was a hotmail account that was of concern and how lovely that the address is that of a cute yellow lab. I would not have thought this would have been unprofessional.... I actually thought that "David" (on the email account) was your former husband, wondering why you continued to use that as your email. I often wondered to myself if this meant you still shared an account. I then would wonder why I was even making note of this (as a concern for you?). I am now giggling at the screen as I think about the ways in which we "read" the lives of others and hold concern and regard for people as we develop relationships.

Joyce: ....Ha! I can picture us now tentatively sitting at our respective computers wondering about each others' lives. Nothing too exciting here. My folks were certain, for some reason, that I was going to come out a boy, and they wanted to name me after my dad, "David." I was number four so I was likely the last opportunity for him to have a namesake. When I ended up a girl they figured "meh, just add an 'a' to the end and pronounce it 'Dah-veeta." So, "no," my email address is not accessible to my ex. I am Davida!

I digress... Back on track -I gradually transitioned from daily use of my previous Hotmail account to the new gmail one. That said, the first time Mary sent back her first set of revisions on my proposal, I completely failed to notice an attachment. Copious and obscene amounts of time passed. Copious. And. Obscene.

Finally, Mary realized: "There is no possible way Joyce could have taken this long to go through my comments. I should check in." Mary carefully inquired by email: "Hi there Joyce, just wondering how things are coming along with my suggestions? Let me know if there's anything I can do." This kind, nudging email prompted me to acknowledge that there must be an attachment that I was missing. I had a "techy" friend help me find it and things got moving from there. This mishap probably spanned four months! Reflecting back upon this now has led me to the following comical but also important insights: 1) I have a traumatic brain injury (TBI) (as mentioned above) that was acquired in 2008. Due to this, learning any new system (i.e. a new email system) is something I now need to be intentional about rather than simply assuming that it will come naturally to me as it had pre-injury. "User friendly" systems are not as friendly to me as they once were. This mishap with the email and attachment served as a good early-stage reminder for me; 2) In the same way that any new system-learning does not come as naturally for me since the accident, the script of human interaction does not either. Since my brain injury, interpersonal engagements that would otherwise seem "normal" (whatever that means) for a functioning brain, are not always easy or normal for me; 3) I think this third factor has little to do with my TBI but rather is just a general commentary regarding the delay that politeness can cause to one's work. I think both Mary and I are much too polite. We tiptoed around each other for four months!

Mary: I wish I was as polite as Joyce. She is one of those rare, precious soles who you wish to role model yourself after....such kindness, generosity, and grace. ......and yeah, I do think that first instance of my quick turnaround with feedback and the "black hole" non-response that ensued was a little concerning for me. Of course, at that time, I had no idea that it was related to new systems and brain activities. I mused to myself, "is she off running a marathon again? or in Costa Rica?" because one aspect of Joyce that I particularly enjoy (but also presents additional challenges) is her penchants for far flung adventures. How many countries did you actually visit during the thesis process? I recall trips to Thunder Bay, Costa Rica, Boston (for the marathon x 2. Bravo you!), New Zealand, I think ... and were there others? If there is one thing I am accustomed to with graduate supervisions it is this vagabond nature of almost every student I work with. Or should I call it following one's bliss? I supervise students who live in yurts in the Yukon, tackle Northern rivers on 45-day journeys, and send me last minute notification that they will be offline for an extended period of time, 
announcing they are pausing their thesis progress to pursue an opportunity to join an expedition. I had not thought much about the four-month hiatus in response other than assuming that Joyce had received the feedback. I was feeling a bit concerned that her lack of response was due to my direct (and abundant) feedback however. "Was she okay with my style and should I have been a bit more delicate given her brain injury, " I wondered?

Joyce: Boy did you nail it - I definitely have a vagabond nature. The many delayed responses throughout our scholarly relationship were often due to this disposition. The particular instance of the 4-month delay however was due to an old/failing computer and both primary and secondary brain injury issues, including an inability to navigate new systems. Before my accident, I had a tendency to get quite focused on a task. This was an advantage for me. Now, this tendency has become a liability to me, as I get hyper focused on one task to the expense of all others. This hyper focus was often the cause of delays in emailing Mary back. While I was once quite skilled in time-management (in my former life) and could spin many plates, completing many tasks in their allotted time frames, I struggle to do this in my post accident life. While I easily recognize that it should be as simple as dividing up the appropriate number of hours in the day for the required tasks, the severity of my TBI headaches multiply when I self-impose time constraints on tasks, and my life begins to lose much of its quality - not to mention that tasks are just not done very well.... This is a particular challenge with cognitive tasks. Physically, I am in as good of shape as ever, which likely frustrated Mary to no end as she listened to stories about my rock climbing, and swimming, and marathons and travelling, and hiking endeavors. "What the heck is this girl putting me on the backburner for? I'm busting my ass to edit her work while she's rock climbing? ROCK CLIMBING????"

Mary: No No...not at all did I think that. Instead, I was thinking WOW! How does she do all that? And good for her that her recovery is aided by all this activity! In fact, I witnessed a bit of this myself when Joyce and I rockclimbed at the gym together one day. Sometimes our feedback sessions in my office were rushed or I was cranky, given my multiple obligations and work stresses. Other times, there were such gaps between writing and feedback sessions that both Joyce (I think) and I struggled to reconnect with the thesis work. Also, in my experience it sometimes seemed that words alone were insufficient for the feedback to be understood and/or to sink in, particularly if we didn't meet in person and I only provided track changes. One day we went rockclimbing at the indoor climbing gym. I found that day to be particularly significant interpersonally but also thesis-wise. It was as if the physical activity opened up pathways in Joyce's brain. I wonder what we sounded like as we swapped climbs, talking the whole time about aspects of her writing or ideas she was assimilating. A very powerful experience for me to think about how to connect with students when providing feedback so that the volume and my direct style don't intimidate or overwhelm them but open up pathways for consideration and discussion. I also giggle thinking back on that day when she declared, "it is like you are stretching on the rock as you warm up".... a true sign of my age and her strong climbing skills as she "warmed up" on climbs far more difficult than what I was climbing.... a shift in the power dynamic of our interactions as well, with her encouraging and supporting me up the rock face.

Joyce: Ahhh - here is a chance for me to reflect more fully on our climbing day! During my Master's thesis defense Mary and I were attempting to ponder what it was about that climbing day that potentially percolated my research efforts. I was at a loss for words (unfortunately not the only instance of this during my thesis work, I can assure you......) There are many factors from the climbing day that helped me develop a "road map" of how to work toward defense success and that deepened my understanding of how to understand and integrate Mary's feedback. As mentioned above, my thesis was an autoethnography, which perhaps some may perceive as a "self-absorbed," pretentious exercise. Mary was open to my approach and process, which I greatly appreciated. She instilled confidence in me, which was most strategically needed on the day we went climbing together. I had been feeling as though I had no idea if I could meet all three of my committee members' recommendations. I didn't even know if I had the capacity to understand them, much less address their feedback in a timely manner. My most poignant memory of that day was when Mary told me (with total conviction) that she had seen me buckle down and progress through an immense volume of track changes and feedback in a stunningly short amount of time, and that I had carried out each recommendation to a "T." This was incredibly good for me to hear as I was feeling some of the effects of my TBI and how they had altered my productivity in the paper writing and revising processes. I can't simply tell myself "Joyce write" anymore. It's not that simple. I struggle to find my own beginning point, my own end point. I struggle to time manage (as mentioned), I struggle to fine tune a "big picture" idea. I fail to communicate clearly - this is one of the most painful losses I've incurred as this was once one of my greatest assets. But when I have small details handed to me in neat packages, in bite sizes that don't overwhelm me (i.e. track-change sizes), I feel productive as I can work through each one and check them off, like I would a list of "to do" items. Through my MA career, I learned that course work and papers were bite size chunks much like the chapter edits of my thesis. They were a good "chewable" size. Maybe this is something everyone feels with a thesis as it is often the biggest work any student has previously endeavored. I had written an undergraduate thesis of 44 pages during my BA, but that hadn't seemed all that different from a regular paper to me..... 
Who knows if some of the differences in my scholastic style between my pre- and post- accident self are due to my TBI or due to age (or other factors)? I was 24 when I finished my BA and 32 when I finished my MA. Back then, I didn't even start a paper until $11 \mathrm{pm}$ the night before it was due. Now, I am useless in the evening. My most productive hours are between $11 \mathrm{am}$ and $5 \mathrm{pm}$. Back then, I had never had anyone edit anything. Now, I find a second pair of eyes notices mistakes that I would never have seen no matter how carefully I'd searched. Back then I worked three jobs while engaging in full time studies. During my MA I was a part-time student. Period.

I'm sure the changes in my scholastic capacity could be attributed to a combination of these age and TBI factors. Whatever the factors, I am infinitely grateful to those professors committed to pedagogical tactics, theories and frameworks that lead them to work with students who require care outside of the norm. Mary was tireless in her concern for me, for my overall welfare and for my success in the program.

Mary: Really? This statement feels too generous of an attribution given what I look back upon as sometimes a "too rushed" impatience with feedback for Joyce and a lot of juggling of priorities. I find academic life to be overall wonderful and entirely exhausting yet liberating and privileged....not dissimilar to my 7 years as a fulltime wilderness trip guide. I wonder sometimes if being a professor is a bit like being on expedition. One needs to exhibit good expedition behavior and an outward thinking mentality given the service, teaching, supervisions, and multiple research projects (often involving multiple stakeholders). One also needs to find time for self-care given the extended hours and near constant demands and intensity. A wilderness trip has a fixed end point and scholarly work does not. Sometimes I feel like I am "on trip," facilitating a group climb from base camp to the top of a peak, but with a less clear and obvious trajectory and summit/goal than one might have if guiding a mountain, for example. How do I facilitate graduate student success with each individual's unique process, learning style, and timeline? How do I set limits as I attempt to prioritize this alongside all the other demands of academic life while also occasionally taking "real" time off?

Joyce: I feel like the scope of this paper just swelled! Mary's last little vignette parallels or applies to everything really. So many things in life never really feel done. They just wrap into life and you always need to be "on" in some capacity once you've committed to something. How well anyone "blends" something in her life feels to me a measure of how well you are undertaking it, or maybe how fully it forms you. Fitness "forms" me. It blends into my life whether I'm home, or away, feeling well or sick. Advocacy too forms me. I seem to fall into it in all spheres of my life and as one opportunity comes to a close, another springs up in its place.

I find though, that scholarly efforts, like writing, seem to stagnate and do not blend effortlessly into my life. I hope this is a growing pain and that I will be able to will myself out of this state as I enjoy writing. If I could make writing blend into my life effortlessly - in my travels, and in my regular life; in scheduled times and in spontaneous ones; in my high times and in my low times; on run-of-the-mill days, and on hectic days; in times of calm and relaxation, or in times of crises and chaos - if writing would come to me equally naturally in all of these states, then I could know that I have blended it well in my life. I would feel some sort of agency over my writing and I would feel a sort of allowance to seek it as a profession or even artistic outlet. I struggle with this in much the same way Mary talks about negotiating time off without neglecting the ongoing activity of an academic.....

Mary: and this dialogue could go on and does (!) as we continue to spend time together in Graduate Student Writing Group and at the climbing gym. Next we will summarize why this matters to us and why it may be important for both students and supervisors (and graduate program directors) to consider.

\section{Postscript and Scholarly Significance}

At the outset, we had considered whether to entitle this final chapter, "Scholarly Significance" or "Discussion," to be more congruent with traditional representations of empirically-researched subjects. We are now cognizant that this paper, similar to our student/supervisory experience, is a blend of empirical and conceptual work and thus have decided to write this section as a postscript, reflecting back on the review of relevant literature and our own storied experiences in drawing conclusions about relationship matters, the value of communication, and the importance of culture and context.

\subsection{Relationship Matters}

These results build upon findings by Grose (2011), Jairam \& Kahl (2012), Mishna \& Rasmussen (2001), and Spaulding \& Rockinson-Szapkiw (2012) (among others) who assert that relationship-building is key to graduate student success. In this instance, relationship was core to Joyce's success and core learning for Mary in how to better mentor students based on their specific needs and life contexts. Mary developed a high level of empathy for Joyce which has been extended to interactions with other students, resonant with Lovitt's (2001) findings that interactions with your supervisor outside of the formal mentor-student role is key to graduate school success. The day at the climbing gym was impactful not only on the relationship but on the learning and process. Mary now deliberately strives to be more 
compassionate and patient with graduate students, having further developed an awareness, through this duo-narrative process, that we all lead lives that are multi-faceted and complex.

Previously, Mary too often assumed that all graduate students possess a high level of confidence and a strong sense of self and that they would welcome direct and voluminous feedback and not be emotionally affected by it. Mary also assumed a basic set of requisite skills and capacities that graduate students (who were somehow mysteriously born with these?) would deploy in navigating the academy and graduate student work. Faculty generally make assumptions about graduate students, including their high level of independence, high marks, critical thinking \& analytic skills and emotional maturity, distinguishing graduate students from undergraduate students (Hartel, 2008). It is not that Joyce was lacking any of this, it was that her capacities (like every individual!) are unique and supervisors need to avoid cookie cutter approaches to supervision. Not all graduate students are created equal, which is often an assumption inherent in the supervisor's approach (Hartel, 2008; Woolhouse, 2002).

\subsection{Communication}

Gill and Burnard (2008) and PGSS (2014) assert that written documentation, regular meetings, and clear timelines can help support student success. But clearly these mechanistic aspects of supervision are generally insufficient although they may not always be. Some students are perhaps looking for structural support moreso than relational engagements. Key to these decisions is communication. As Taylor and Dawson (2010) have concluded, it is beneficial for supervisors to help students facilitate their project in a manner that proffers them ultimate agency in their research endeavor. Co-determining the approach with the supervisor will, in the end, result in higher degrees of success without loss of agency. As De Kleijn, Mainhard, Meijer, Pilot, and Brekelmans' (2012) and Lovitts (2001) conclude, graduate student success involves a careful balance of control and affiliation and the degrees of each will be student dependent. There is no cookie-cutter formula for this equation either and the student/supervisor experience requires flexibility and heavy doses of communication, resonant with our experiences as well.

\subsection{Culture and Context}

The importance of culture and an individual's context cannot be underscored enough. With student cohorts becoming more and more diverse, with disparities in financial resources, and students' varying abilities, a supervisor needs to be receptive and responsive to an individual's culture and context (Acker \& Hague, 2015). Acker and Hague (2015) researched 27 ethno-culturally diverse graduate students, uncovering that students believed that white students, have better access to resources, information and faculty attention. How might supervisors develop a level of cultural competency that prepares them to mentor students in this increasingly diverse and globalized society?

There is also an implicit, compulsory demand for physical, mental, and emotional able-bodiedness within the academy, where good students and effective instructors are not represented by people with disabilities (Damiani \& Harbour, 2015). For many graduate students with disabilities, the hidden curriculum underpinning ableist expectations and implicit messages may have an impact not only on academic success but on retention and degree completion (Damiani \& Harbour, 2015). Imagine if Mary had not known that Joyce had a brain injury at the outset? Imagine if Mary had reacted negatively to Joyce not noticing the attachment? Imagine if these matters had never been discussed? Joyce and Mary co-determined that in person meetings would be beneficial to Joyce's progress rather than continuing with back and forth email exchanges and attachments with multiple track changes and comments. Also poignant was to learn that when they rockclimbed together, the feedback made even more sense for Joyce and leveled the power dynamic (Hemer, 2012). When it comes to the student-supervisor relationship, co-fostering a rapport and being sensitive to context is critical. Co-establishing the parameters of the student-supervisor working relationship and co-determining expectations are always context specific (Gardner \& Barnes, 2014). While many students seek an affiliation/relational approach (Grose, 2011), it is important to remember that not all do. As previously mentioned, some students are perhaps looking for structural support moreso than relational engagements.

\subsection{Concluding Remarks}

Finally, what tips do we have in light of all this? Visit the Oxford Learning Institute website. Engage in student/supervisor reflexive praxis. Write together and to each other as we have here. Share it! Researching graduate programs and supervisors in some depth would serve the student well. Does the program "fit" with the student-researcher's intent and purpose? What are the required courses and residency requirements? What is the cost, both time commitment and financial? What is the geographic locale? What communities of practice exist within the graduate program and in the community itself to support the students" efforts? These "standard" questions will help initially focus a student's program priorities. We believe that students would be served well by meeting with their potential supervisor on multiple occasions prior to applying to graduate school given the centrality of this relationship. What is the supervisor's approach to mentorship? What is her relevant content and methodological expertise? What other students and theses has she supervised? The student might wish to speak with former students about their 
experiences.

The supervisor may wish to more fully consider the impact of supervision on workload. Some professors are "required" to supervise students. In many universities, this is optional "work." Who are we serving and how are we being served when taking on student supervisions? Might we be better informed if we first meet with students as well and ask for writing samples? This has become common practice for Mary as her graduate student load has increased over the years. What type of students best "fit" with/in our own skills and capacities? Many of us are more task-oriented when it comes to thesis supervision, others more relationship-oriented. Consideration of what learning style and approach will best match and support a student's style merits careful thought prior to entering into a student/supervisor mentorship. Saying "no" as a supervisor might best serve everyone's interests.

What Joyce and Mary now know is that their relationship is stronger as a result of this shared experience and written reflections upon it. We have learned, grown, and evolved as a result of this collaborative effort. We have been formed and transformed by the other and in relationship. What more could we ask from what started as a chance meeting?

\section{References}

Acker, S., \& Hague, E. (2015). The struggle to make sense of doctoral study. Higher Education Research \& Development, 34(2), 229-241. http://dx.doi.org/10.1080/07294360.2014.956699

American Psychological Association. (2015). Feel like a fraud? Retrieved from http://www.apa.org/gradpsych/2013/11/fraud.aspx

Amundsen, C., \& McAlpine, L. (2009). 'Learning supervision': Trial by fire. Innovation in education and teaching international, 46(30), 331-342. http://dx.doi.org/10.1080/14703290903068805

Armstrong, S., Allinson, C. W., \& Hayes, J. (1997). The implications of cognitive style for the management of student-supervisor relationships. Educational Psychology, 17(1\&2), 209-217. http://dx.doi.org/10.1080/0144341970170116

Atkinson, P. (1990). The ethnographic imagination. London: Routledge.

Charmaz, K., \& McMullen, L. M. (2011). Five ways of doing qualitative analysis: Phenomenological psychology, grounded theory, discourse analysis, narrative research, and intuitive inquiry. The Guilford Press: New York, New York.

Damiani, M. L., \& Harbour, W. S. (2015). Being the wizard behind the curtain: Teaching Experiences of graduate teaching assistants with disabilities at U.S. universities. Innovations in Higher Education, 40, 339-413. http://dx.doi.org/10.1007/s10755-015-9326-7

de Kleijn, R. A. M., Mainhard, T., Meijer, C. P., Pilot, A., \& Brekelmans, M. (2012). Master's thesis supervision: relations between perceptions of the supervisor-student relationship, final grade, perceived supervisor contribution to learning and student satisfaction. Studies in Higher Education, 37(8), 925-939. http://dx.doi.org/10.1080/03075079.2011.556717

Fraser, R., \& Mathews, A. (1999). An evaluation of the desirable characteristics of a supervisor. Australia: University of Western Australia.

Galt, V. (2013, October $9^{\text {th }}$ ). The all-important graduate student-supervisor relationship. University Affairs.

Gardner, S. K., \& Barnes, B. J. (2014). Advising and mentoring doctoral students: A handbook. Create Space Independent Publishing Platform.

Gill, P. \& Burnard. P. (2008). The student supervisory relationship in the $\mathrm{PhD/doctoral} \mathrm{process.} \mathrm{British} \mathrm{Journal} \mathrm{of}$ Nursing, 17(10), 668-671. http://dx.doi.org/10.12968/bjon.2008.17.10.29484

Gray, P. W. \& Jordan, S. R. (2012). Supervisors and academic integrity: supervisors as exemplars and mentors. Journal of Academic Ethics, 10, 299-311. http://dx.doi.org/10.1007/s10805-012-9155-6

Grose, J. D. (2011). TA tales: [re]storying the teaching and learning experiences of university teaching assistants (Unpublished doctoral dissertation). Brock University, St. Catharines, ON.

Hartel, R.W. (2008). Faculty expectations of graduate students. Hartel, R. W., \& Klawitter, C. P. (Eds.), Careers in Food Science: From Undergraduate to Professional (pp. 117-126). Wisconsin: Springer. http://dx.doi.org/10.1007/978-0-387-77391-9_12

Hemer, S. R. (2012). Informality, power and relationships in postgraduate supervision: supervising PhD candidates over coffee. Higher Education Research \& Development, 31(6), 827-839.

http://dx.doi.org/10.1080/07294360.2012.674011 
Jairam, D., \& Kahl, D. H. (2012). Navigating the doctoral experience: The role of social support in successful degree completion. International Journal of Doctoral Studies, 7, 311-330.

Lovitts, B. E. (2001). Leaving the ivory tower: The causes and consequences of departure from doctoral study. Lanham, Maryland: Rowan and Littlefield.

Mainhard, T., van der Rijst, R., van Tartwijk, J., \& Wubbels, T. (2009). A model for the supervisor-doctoral student relationship. Journal of Higher Education Policy and Management, 58, 359-373. http://dx.doi.org/10.1007/s10734-009-9199-8

Mishna, F., \& Rasmussen, B. (2001). The learning relationship: working through disjunctions in the classroom. Clinical Social Work Journal, 29(4), 387-399. http://dx.doi.org/10.1023/A:1012271331208

Norris, J., Sawyer, R. D., \& Lund, D. E. (2012). Dialogic methods for social, health, and educational research. Walnut Creek, CA: Left Coast Press.

Patton, M. Q. (2014). Qualitative research \& evaluation and methods ( $4^{\text {th }}$ ed.). London, Sage.

Penner, J. (2014). Anachronistic me: An autoethnographic account of recovery through volunteerism

Retrieved on July 1, 2015 from https://dr.library.brocku.ca/bitstream/handle/10464/5389/Brock_Penner_Joyce_2014.pdf?sequence=1<https://dr.lib rary.brocku.ca/bitstream/handle/10464/5389/Brock_Penner_Joyce_2014.pdf?sequenc\%09e=1>

Polkinghorne, D. (1988). Narrative knowing and the human sciences Albany, NY: State University of New York Press.

Post-Graduate Students' Society (PGSS) of McGill University (2014). Health of student supervisor relationship at McGill University. PGSS: Montreal, Quebec.

Psych. Central. (2015). What I wish I knew in grad school: Current and former students share 16 tips. http://psychcentral.com/lib/what-i-wish-i-knew-in-grad-school-current-and-former-students-share-16-tips/0007541

Silverman, D. (1998) Qualitative research: Theory, method and practice. London, Sage.

Skarakis-Doyle, E., \& McIntyre, G. (2008). The university of western Ontario teaching support centre. Western Graduate Studies. London, ON.

Spaulding, L. S., \& Rockinson-Szapkiw. (2012). Hearing their voices: Factors doctoral candidates attribute to their persistence. International Journal of Doctoral Studies, 7, 200-220.

Taylor, P. A., \& Dawson, V. (2010). Critical reflections on a problematic student-supervisor relationship. In Malone, J.A., Atweh, B. \& Northfield, J. (Eds.), Research and Supervision in Mathematics and Science Education (pp. 105-138). New York: Routledge.

Woolhouse, M. (2002). Supervising dissertation projects: expectations of supervisors \& students. Innovations in Education and Teaching International, 39(2), 137-144. http://dx.doi.org/10.1080/14703290252934586

This work is licensed under a Creative Commons Attribution 3.0 License. 